\author{
Chapter in THE ROUTLEDGE COMPANION TO HEALTH HUMANITIES \\ eds P Crawford, B Brown \& A Charise.
}

\title{
CO-DESIGN AS A DEMOCRATIZING FORCE
}

\author{
Alastair Macdonald \\ Introduction \\ Design is succinctly summarized as "a set of practices aimed at realizing a certain desirable future" (Storni, 2013: 51) \\ and, as such, is predicated on the idea that the status quo can be improved. Immediately, a number of questions \\ arise: Whose desirable future, and who should be involved in defining and deciding this? How to move toward an \\ idea of an improved future that we have not yet had the opportunity to experience? This chapter sets out to provide \\ an introductory overview of design's more recent practices and preoccupations, its contribution to the field of \\ health care, and how these practices attempt to improve the health-care experience - for both those receiving it and \\ those involved in its delivery - by helping realize some of the aspirations of the health humanities.
}

\section{Design in the health-care setting}

Within health care, design is a field advancing on a number of fronts; varied contributions are evidenced in Tsekleves and Cooper (2016). Robert and Macdonald (2017) characterize the health-care setting as follows:

\begin{abstract}
In terms of a service environment, several aspects of healthcare make it rather different from other sectors, not least its sheer scale, variety and complexity, as well as the (often) fragility, vulnerability and dependency of its clients. Healthcare organizations and services are also typically complex, hierarchical, and highly socio-technical settings. The dynamics within interdisciplinary healthcare teams are often as complex and hierarchical as those between teams and their patients. (118)
\end{abstract}

This immediately identifies a number of problematic issues within a largely biomedical paradigm that design, if it is to be involved, needs to acknowledge and address. The setting can be likened to a complex service ecosystem with a large cast of interacting players and agents: cohorts of individuals each with their differentiated roles, tasks, behaviors, and interactions; the agents and mechanisms of threats to health care and treatment (such as infection); and the design of the environment and its positive or negative effects on recovery and wellbeing.

If a future is to be desirable, shared, and democratic - for patient, carer, and health-care provider alike-then all need to be involved in envisioning, creating, and realizing that future. Co-design, defined as "the meaningful involvement of end users in the design process" (Design Council, 2017), is now a common and well-established practice. Its roots lie in the 1970s Scandinavian "participatory design" (PD) movement, a phrase "often used as an umbrella term for participatory, co-creation and open design processes" (Chisholm, n.d.).

It is therefore worthwhile to differentiate design approaches that are merely consultative as distinct from truly meaningful participation. Savory (2010) provides a useful framework for incorporating patient and public involvement in translative health-care research, and both Arnstein and the New Economics Foundation (NEF) provide models representing the shifts in "people power." Arnstein's Ladder of Citizen Participation (1969) starts with "manipulation," and moves up through a number of stages including "consultation" and "partnership," eventually leading to "citizen control." In a simplified and more contemporary interpretation of this, NEF's Ladder of Engagement (2014) categorizes different types of approaches, progressively shifting from "doing to" (e.g., coercion), through "doing for," to "doing with" (i.e., co-production) at the top. Design's thrust is habitually toward the top end of this ladder.

\section{A democratic space}

Having declared the intent to co-design, and to bring together the relevant stakeholders to do so, how does one address the particularly problematic issues arising from health care and its setting (such as hierarchical roles) to 
create a space or forum removed from that setting? How might habituated behaviors and power dynamics in healthcare settings be positively challenged by co-design? How can co-design in such spaces be practiced in democratic ways? Here, it is valuable to describe two approaches. One is the creation of a "publics," an open and neutral space, and the other an "infrastructuring," with materials and activities to enable co-design to take place within this space. Within this open space, the assembled team are "individuals bound by a common cause" (Le Dantec and DiSalvo, 2013: 243) that together create "a dynamic organization of individuals and groups formed by the desire to address an issue" (254). Turner (1969) coined the term "communitas," defined as a union of equal members. The designer does not have expertise in the clinical or care sense, nor is s/he a "virtuoso of experience" (Sanders, 2001); to enable "designing" to be carried out in a co-design approach by all stakeholders, the activities within this space need a degree of "infrastructuring" (Bjorgvinsson et al., 2010). The intention of such infrastructuring is "to capture particular views and ways of engaging when designing complex sustainable systems" (Seravalli and Eriksen, 2017: 246) and to allow for the designing of situations, activities, and materials to enable a "greater proportional symmetry" between the stakeholders involved (Strickfaden and Devlieger, 2011: 208). Examples might be materials such as visual stimulus cards, personas, storyboarding and narratives, design games, activities such as role-play, and enactment with paper mock-ups or functional prototypes to help reconceive and simulate a new hospital food management and nutrition monitoring system (Macdonald et al., 2012). Another example might be to reimagine how physical rehabilitation following stroke, using visualization techniques, could assist improved understanding and communication between therapist and patient (Loudon et al., 2014).

\section{Building to think}

These materials, along with the format and structure of these co-design sessions, not only invite contributions to ensure that all voices have a say; they also move beyond the capture of experience and insight to embody these voices in prototype and mock-up form - to help bring a degree of tangibility to ideas, whether these are for equipment, procedures, or services.

Sanders and Stappers discuss designers' ability to "make things that describe future objects" and cite how prototyping can play a number of roles, for example, to "allow the testing of a hypothesis" because prototyping "allows people to experience a situation that did not exist before" (2014: 6). It is worth stressing that in the inclusive co-design approach it is not the designer who is doing the designing. Rather, it is the stakeholders-enabled by the approaches, spaces, types of practice, and materials habitually used in design practice- who become actively involved in this collaborative venture.

In the context of using prototyping in policy making, Siodmok (2014) states, "to prototype generates imperfect truths but with the right approach it also generates data about the future" and also "evidence of what works and, more importantly, what does not, can be very powerful." In the health-care setting, Coughlan et al. (2007) cite cases of the effectiveness of "rapid prototyping," discussing its value in such terms as "building to think," "giving permission to explore new behaviors ... in a nonthreatening, low-risk way" (9), as "learning tools" and "transitional objects ... that support a change from a current behavior to a new behaviour" (10). Evidence-based design is very much about designing, making, prototyping, and testing with the intention of ultimately moving beyond research towards implementation. It involves thinking beyond the now, and toward the future.

\section{Designerly and design-like}

Until relatively recently, the design profession was hung up on the idea that it was the profession to be doing all the designing. If one looks broadly at design since the mid-twentieth century one can see, comparable to the shifts in approach to engagement and participation outlined above, a paradigm shift from that of the consultant designer designing products for people to the late twentieth- and early twenty-first-century paradigm where the designer is collaborating much more with others. Increasingly, this work is further informed by interdisciplinary teams and the public, through what is much more widely understood and accepted as co-design today. This reflects the democratization of design activity, epitomized by the work of the Scandinavian PD movement, that is now more widely adopted and adapted. But what if this trajectory was taken to its logical conclusion? Could one have people designing without the need for designers at all? Is that possible? In fact, a form of this has already occurred using the experience-based co-design (EBCD) approach:

$[E B C D]$ is an approach that enables staff and patients (or other service users) to co-design services and/or care pathways, together in partnership. The approach is different to other service improvement techniques. (Point of Care, 2018) 
Donetto et al. (2014) summarize a decade of EBCD's achievements in improving patient experiences, using the approach first piloted in a head and neck cancer service at a National Health Service hospital in England. This form of "designing" has been able to achieve what design has been unable to in terms of the consistent application, refinement, and uptake of the EBCD method in over 60 health-care organizations internationally. EBCD poses some interesting questions and challenges for design. Robert and Macdonald (2017) develop this discussion by differentiating "designerly" from "design-like" approaches and methods, highlighting the strengths, weaknesses, and the types of outcomes each approach tends to produce.

\section{Co-design as anti-structure}

Co-design practices and approaches, such as those described above, act to establish an "anti-structure" (Turner, 1969) capable of resisting and counteracting a hegemonic medicalized service paradigm. In its place, co-design provides opportunities to create an alternative space where no ideas are "off the table." This alternative space, and the types of materials, activities, and practices it involves, describes a shift "away from a technocratic view of innovation towards one that includes social innovation-innovation that arises out of social interactions ... and actions that arise from the constitutions of a public" (Le Dantec and DiSalvo, 2013: 247). The creation of that neutral and open space, supported-that is, infrastuctured-through appropriately inclusive materials and activities allows for a "plurality of voices, opinions and positions" (Strickfaden and Devlieger, 2011: 208) that assist thinking and building towards more appropriate future "solutions." These are the futures that are co-constructed and reconciled from the multiple narratives and desires of all those involved. As a consequence, such co-designed futures challenge epistemological privilege in conventional health-care knowledge and experience.

\section{References}

Arnstein, S. R. (1969). A Ladder of Citizen Participation. Journal of the American Planning Association, 35 (4): 216-224.

Björgvinsson, E., Ehn, P. and Hillgren, P. A. (2010). Participatory Design and Democratizing Innovation, in PDC'10: Proceedings of the 11th biennial participatory design. Conference, Sydney, Australia, 29 November - 3 December 2010. New York: ACM Press, 41-50.

Chisholm, J. n.d. What is co-design? Design for Europe: Available at http://designforeurope.eu/whatcodesign (Accessed 23/11/2019).

Coughlan, P., Fulton Suri, J. and Canales, K. (2007). Prototypes as (design) tools for behavioral and organizational change: a design-based approach to help organizations change work behaviors. Journal of Applied Behavioral Science, 43(1): 122-134.

Design Council. (2017). The A-Z of Co-Design. Accessed 31 July 2018. Available at: www.designcouncil. org.uk/z-co-design (Accessed 18/2/2019).

Donetto, S., Tsianakas, V. and Robert, G. (2014). Using Experience-Based Co-Design to Improve the Quality of Healthcare: Mapping Where We Are Now and Establishing Future Directions. London: King's College London. Available at: www.kcl.ac.uk/nursing/research/nnru/publications/Reports/ EBCD-Where-are-we-now-Report.pdf (Accessed 20/9/2018).

Le Dantec, C.A. and DiSalvo, C. (2013). Infrastructuring and the Formation of Publics in Participatory Design. Social Studies of Science, 43(2): 241-264.

Loudon, D., Taylor, A. and Macdonald, A.S. (2014). The Use of Qualitative Design Methods in the Design, Development and Evaluation of Virtual Technologies for Healthcare: Stroke Case Study. In: M. Ma, L.C. Jain and P. Anderson, eds, Virtual and Augmented Reality in Healthcare 1. Berlin Heidelberg: Springer-Verlag: 371-390.

Macdonald, A.S., Teal, G., Bamford, C. and Moynihan, P. J. (2012). Hospitalfoodie: An Inter-Professional Case Study of the Redesign of the Nutritional Management and Monitoring System for Vulnerable Older Hospital Patients. Quality in Primary Care, 20 (3): 169-177.

New Economics Foundation. (2014). Co-Production: Theory and Practice. [online] Available at: https:// prezi.com/eitdkeaoly8t/co-production-theory-and-practice/?webgl=0 (Accessed 31/7/2018).

Point of Care. (2018). EBCD: Experience-Based Co-design Toolkit. Available at: www.pointofcarefoun dation.org.uk/resource/experience-based-co-design-ebcd-toolkit/(Accessed 31/7/2018). 
Robert, G. and Macdonald, A. S. (2017). Co-design, organisational creativity and quality improvement in the healthcare sector: 'designerly' or 'design-like'? In: D. Sangiorgi and A. Prendiville, eds, Designing for service. London: Bloomsbury. 9: 117-130.

Sanders, E.B.-N. (2001). Virtuosos of the Experience Domain. [pdf] Maketools. Available at: www.make tools.com/articles-papers/VirtuososoftheExperienceDomain_Sanders_01.pdf (Accessed 31/7/2018).

Sanders, E. B.-N. and Stappers, P. J. (2014). Probes, Toolkits and Prototypes: Three Approaches to Making in Codesigning. CoDesign: International Journal of CoCreation in Design and the Arts, 10 (1): 5-14.

Savory, C. (2010). Patient and Public Involvement in Translative Healthcare Research. Clinical Governance: An International Journal, 15: 191-199.

Seravalli, A. and Eriksen, M. A. (2017). Beyond Collaborative Services: Service Design for Sharing and Collaboration as a Matter of Commons and Infrastructuring. In: D. Sangiorgi and A. Prendiville, eds, Designing for Service. London: Bloomsbury: 237-250.

Siodmok, A. (2014). Designer policies. [pdf] RSA Journal (4): 28-29. Available at: https://www.thersa. org/discover/publications-and-articles/journals/rsa-journal-issue-4-2014/ (Accessed 23/11/2019).

Storni, C. (2013). Design for Future Uses: Pluralism, Fetishism and Ignorance. Available at: www. nordes.org/opj/index.php/n13/article/viewFile/276/258 (Accessed 31/7/2018).

Strickfaden, M. and Devlieger, P. (2011). Empathy Through Accumulating Techné: Designing an Accessible Metro. The Design Journal, 14 (2): 207-230.

Tsekleves, E. and Cooper, R. (Eds) (2017). Design for Health. Abingdon: Routledge.

Turner, V. (1969). The Ritual Process: Structure and Anti-Structure. Cornell Paperbacks: Cornell University Press. 